\title{
Oxidative Degradation of Atropine Drug by Permanganate Ion in Perchloric and Sulfuric Acid Solutions: A Comparative Kinetic Study
}

\author{
Ahmed Fawzy ${ }^{1,2, ~ *, ~ I s h a q ~ A . ~ Z a a f a r a n y ~}{ }^{1}$, Fahd A. Tirkistani ${ }^{1}$, Basim H. Asghar ${ }^{1}$ \\ ${ }^{1}$ Chemistry Department, Faculty of Applied Science, Umm Al-Qura University, Makkah, Saudi Arabia \\ ${ }^{2}$ Chemistry Department, Faculty of Science, Assiut University, Assiut, Egypt
}

Email address:

afsaad13@yahoo.com (A. Fawzy), iazaafarany@uqu.edu.sa (I. A. Zaafarany),drfahd999@gmail.com (F. A. Tirkistani), bhasghar@uqu.edu.sa (B. H. Asghar)

*Corresponding author

\section{To cite this article:}

Ahmed Fawzy, Ishaq A. Zaafarany, Fahd A. Tirkistani, Basim H. Asghar. Oxidative Degradation of Atropine Drug by Permanganate Ion in Perchloric and Sulfuric Acid Solutions: A Comparative Kinetic Study. Advances in Biochemistry. Vol. 4, No. 5, 2016, pp. 58-65. doi: $10.11648 /$ j.ab.20160405.12

Received: August 28, 2016; Accepted: September 5, 2016; Published: October 18, 2016

\begin{abstract}
The kinetics of oxidations of atropine (ATR) by permanganate ion in both perchloric and sulfuric acid solutions was studied using spectrophotometric technique at a constant ionic strength of $1.2 \mathrm{moldm}^{-3}$ and at $25^{\circ} \mathrm{C}$. In both acids, the reactions showed a first order dependence with respect to [permanganate], whereas the orders with respect to [ATR] and $\left[\mathrm{H}^{+}\right]$ were found to be less than unity. The effect of acid concentration suggests that the reactions were acid-catalyzed. Variation of either ionic strength or dielectric constant of the medium had no effect significantly on the oxidation rates. The reactions mechanism adequately describing the kinetic results was proposed. In both acids, the main oxidation products of atropine were identified by spectral and chemical analyses as tropine and phenylmalonic acid. Under comparable experimental conditions, the oxidation rate of atropine in sulfuric acid was approximately three times higher than that in perchloric acid. The reactions constants involved in the different steps of the reactions mechanism have been evaluated. With admiration to the rate-limiting step of these reactions, the activation parameters have been evaluated and discussed.
\end{abstract}

Keywords: Atropine, Permanganate, Oxidation, Kinetics, Mechanism

\section{Introduction}

Alkaloids are naturally occurring compounds that act on a diversity of metabolic systems in humans and other animals. They are produced by various organisms such as bacteria, fungi, plants, and animals. Alkaloids have significant pharmacological activities as antimalarial, antiasthma, anticancer, cholinomimetic, antibacterial, psychotropic and stimulant activities [1-3]. Among the most famous of the alkaloids is tropine alkaloid or atropine (ATR) which is an anticholinergic drugcontaining two cyclic structures (alicyclic nitrogen-containing alcohol tropine and aromatic tropic acid) joined by an ester linkage [4]. This structure allows for its rapid absorption through the blood-brain barrier. Atropine is structurally similar to cocaine as illustrated below.<smiles>CN1C2CCC1CC(OC(=O)[C@H](CO)c1ccccc1)C2</smiles>

Atropine<smiles>COC(=O)C1CC2CCC(C1)N2C</smiles>

Cocaine
Atropine occurs naturally in plants in the nightshade family including deadly nightshade, Jimson weed and mandrake [5]. It is a secondary metabolite of such plants and serves as a drug with a wide variety of effects. Atropine is considered as a core medicine in the World Health Organization (WHO), which is a list of minimum medical needs for a main health care system. It is a competitive antagonist for the muscarinic acetylcholine receptor. 
Furthermore, it is the most essential drug in the treatment of nerve agent poisoning. Its degradation by microorganisms has been reported by several groups [6] and in the initial stage, the hydrolysis of the ester linkage to give two separate cyclic components takes place.

Oxidation reactions are very important in organic synthesis. Among the important oxidizing agents, permanganate ion is widely used in the oxidations of many organic compounds in neutral, alkaline and acidic media [717]. The mechanism of oxidation reactions by permanganate ion is governed by $\mathrm{pH}$ of the medium [18]. During oxidation by permanganate, it is evident that the Mn (VII) in permanganate is reduced to various oxidation states in acid, alkaline and neutral media. In acid media, permanganate ion $\left(\mathrm{MnO}_{4}^{-}\right)$can exist in several different forms, $\mathrm{HMnO}_{4}, \mathrm{H}_{2} \mathrm{MnO}_{4}{ }^{+}, \mathrm{HMnO}_{3}$, and $\mathrm{Mn}_{2} \mathrm{O}_{7}$ depending on the nature of the reductant. The oxidant has been assigned with an inner-sphere and an outer-sphere mechanism pathways in their redox reactions [19, 20]. In general, reduction of permanganate ion in acid medium goes to either $\mathrm{Mn}^{\mathrm{IV}}$ or $\mathrm{Mn}^{\mathrm{II}}$, where the reduction potential of the $\mathrm{Mn}^{\mathrm{VII}} / \mathrm{Mn}^{\mathrm{IV}}$ couple is $1.695 \mathrm{~V}$ and that of the $\mathrm{Mn}^{\mathrm{VII}} / \mathrm{Mn}^{\mathrm{II}}$ couple is $1.51 \mathrm{~V}$ [21].

Although some reports on the oxidation of atropine by some oxidants have been published [22-26], there is a lack of literature on the kinetics of oxidation of this drug by permanganate ion in acid solutions. This observation prompted us to investigate the title reactions. The objectives of the present study are to check the reactivity of atropine drug towards permanganate ion in different acid solutions, and to propose the oxidations mechanism of such drug to understand its interaction with metal ions and its mode of action in biological systems.

\section{Experimental}

\subsection{Materials}

The chemicals employed in the present work were of reagent grade and their solutions were prepared by dissolving the samples in bidistilled water. The stock solution of atropine was prepared by dissolving the sample, atropine sulfate monohydrate $\left(\mathrm{C}_{17} \mathrm{H}_{23} \mathrm{NO}_{3}\right)_{2} \cdot \mathrm{H}_{2} \mathrm{SO}_{4} \cdot \mathrm{H}_{2} \mathrm{O}$ (Aldrich), in

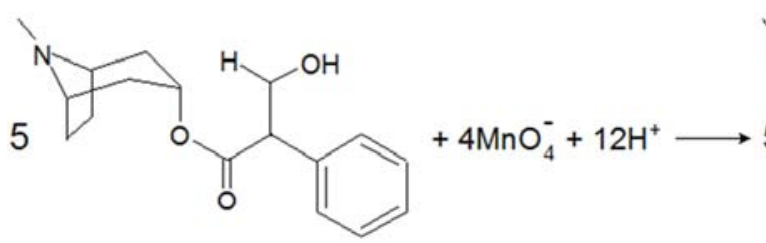

Atropine

The above stoichiometric equation agrees with the product characterization. Tropine and phenylmalonic acid as the main reaction products of atropine were identified by spectral analysis as described elsewhere [25, 28-30]. Tropine was also identified by its hydrazone derivative [28]. bidistilled water. Potassium permanganate freshly solution was prepared and standardized as reported earlier [27]. Sodium perchlorate and acetic acid were used to attain the required ionic strength and dielectric constant of the reactions medium, respectively.

\subsection{Kinetic Measurements}

The kinetic measurements have been followed under pseudo-first order conditions where atropine drug was existed in a large excess over that of permanganate. Initiation of the reactions were done by mixing the formerly thermostatted solutions of permanganate and atropine that also contained the required amounts of the acid and $\mathrm{NaClO}_{4}$. The courses of the reactions were followed by monitoring the decay in the absorbance of permanganate as a function of timeat its absorption maximum $(\lambda=525 \mathrm{~nm})$, whereas the other constituents of the reaction mixtures did not absorb considerably at this wavelength. The absorption measurements were done in a temperature-controlled Shimadzu UV-VIS-NIR-3600 double-beam spectrophotometer.

First order plots of $\ln$ (absorbance) versus time were recorded to be straight lines up to at least $75 \%$ of the reactions completion. The observed first order rate constants $\left(k_{\text {obs }}\right)$ were calculated using non-linear least-squares fitting to the first order dependence of the absorbance versus time plots. The rate constants were the main values of at least three kinetic measurements. The rate constants were reproducible to within $3-4 \%$.

\section{Results}

\subsection{Stoichiometry and Product Identification}

Reaction mixtures containing various amounts of permanganate ion and atropine at constant $\left[\mathrm{H}^{+}\right]$, ionic strength, and temperature were allowed to react for $24 \mathrm{~h}$ in closed vessels for completion of the oxidation reactions. The unconsumed [permanganate] was determined spectrophotometrically at $525 \mathrm{~nm}$. The results indicated that four moles of permanganate are consumed by five mole of atropine drug to yield the oxidation products as shown in the following equation,

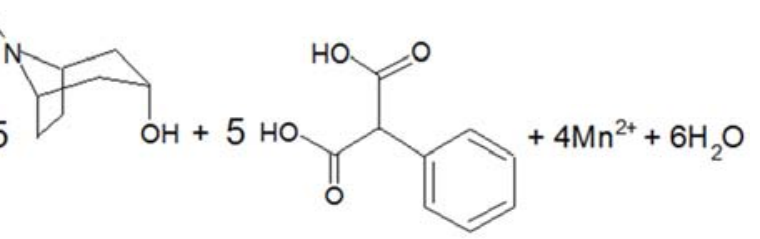

Tropine Phenylmalonic acid

\subsection{Spectral Changes}

The spectral scans during the oxidation of atropine by permanganate ion in perchloric and sulfuric acid solutions are shown in Fig. 1 (a) and (b), respectively. It was shown that there are gradual disappearance of permanganate band at its absorption maximum $(\lambda=525 \mathrm{~nm})$ as a result of its reduction 
by atropine substrate.

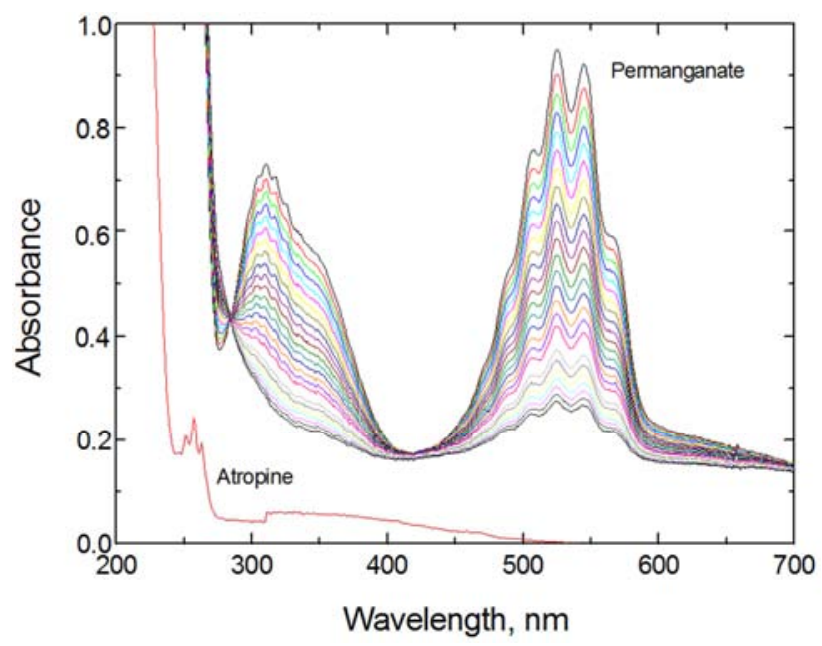

(a)

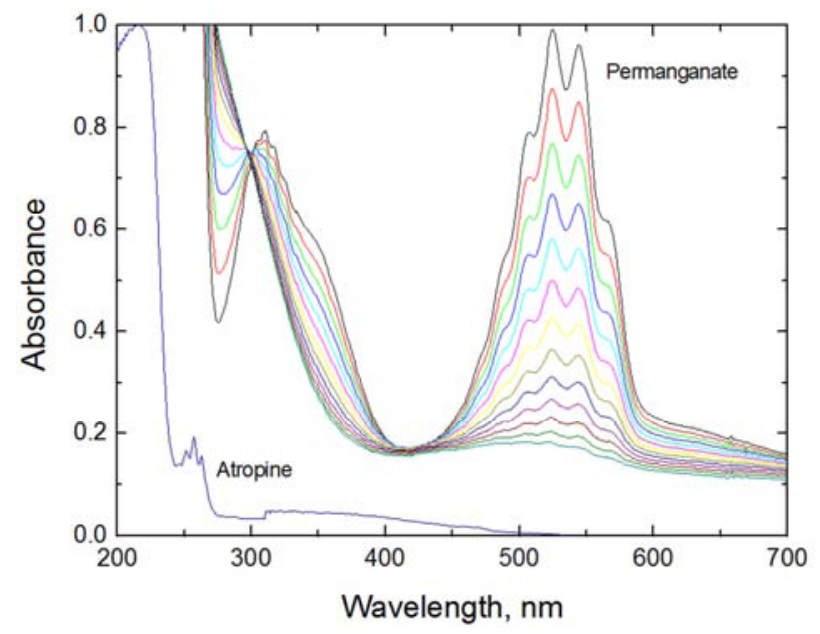

(b)

\subsection{Order of Reactions}

The orders of the reactions with respect to the reactants were determined from the slopes of the $\log k_{\text {obs }}$ versus $\log$ (conc.) plots by varying the concentrations of atropine and acids, in turn, while keeping other conditions constant.

Permanganate ion oxidant was diverse in the concentration range of $(1.0-10.0) \times 10^{-4} \mathrm{~mol} \mathrm{dm}^{-3}$ while the rest of the reactant concentrations were kept constant. Both $\mathrm{pH}$ and temperature were also reserved constant. It has been found that, plots of $\ln$ (absorbance) versus time were linear up to about $75 \%$ of the reactions completion. Furthermore, the increase in $\left[\mathrm{MnO}_{4}{ }^{-}\right]$did not change the oxidation rates as listed in Table 1. These results indicate that the order of the reactions with respect to the oxidant is confirmedto be one.

The observed first order rate constants were measured at various concentrations of atropine keeping others constant. Plots of $k_{\mathrm{obs}}$ versus [ATR] were found to be linear with positive intercepts on $k_{\mathrm{obs}}$ axes in both perchloric and sulfuric acid solutions as shown in Fig. 2 confirming the less than unit order dependences with respect to atropine concentration.

The influence of both perchloric and sulfuric acid on the rates was investigated by varying the hydrogen ion concentration in the range of $0.2-1.2 \mathrm{~mol} \mathrm{dm}^{-3}$, keeping all other reactants concentrations constant. The rate constants increased with increasing acid concentration (Table 1) and the oxidation rate in sulfuric acid was approximately three times higher than that in perchloric acid. Plots of $\log k_{\mathrm{obs}}$ versus $\log \left[\mathrm{H}^{+}\right]$were also linear with slopes of 0.81 and 0.79 in perchloric and sulfuric acid solutions, respectively, Fig. 3, suggesting that the orders of reactions with respect to [acid] were less than unity.

Figure 1. (a, b). Spectral changes during the oxidations of atropine by permanganate ion in: (a) perchloric, and (b) sulfuric acid solutions. [ATR] $=1.2 \times 10^{-2},\left[\mathrm{MnO}_{4}^{-}\right]=4.0 \times 10^{-4},\left[\mathrm{H}^{+}\right]=0.5$ and $\mathrm{I}=1.2 \mathrm{moldm}^{-3}$ at $25^{\circ} \mathrm{C}$. Scanning time intervals $=2.0 \mathrm{~min}$.

Table 1. Effect of variation of $\left[\mathrm{MnO}_{4}^{-}\right],[\mathrm{ATR}],\left[\mathrm{H}^{+}\right]$and I on the observed first order rate constants ( $k_{\text {obs }}$ ) in the oxidations of atropine by permanganate ion in perchloric and sulfuric acid solutions at $25^{\circ} \mathrm{C}$. Experimental error $\pm 3 \%$.

\begin{tabular}{|c|c|c|c|c|c|}
\hline \multirow{2}{*}{$10^{4}\left[\mathrm{MnO}_{4}^{-}\right]\left(\right.$moldm $\left.^{-3}\right)$} & \multirow{2}{*}{$10^{2}[\mathrm{ATR}]\left(\mathrm{moldm}^{-3}\right)$} & \multirow{2}{*}[\mathrm{H}^{+}]{$\left(\mathrm{moldm}^{-3}\right)$} & \multirow{2}{*}{$I\left(\right.$ moldm $\left.^{-3}\right)$} & \multicolumn{2}{|l|}{$10^{3} k_{\text {obs }}\left(\mathrm{s}^{-1}\right)$} \\
\hline & & & & Perchloric & Sulfuric \\
\hline 1.0 & 1.2 & 0.6 & 1.2 & 9.2 & 25.9 \\
\hline 2.0 & 1.2 & 0.6 & 1.2 & 8.6 & 24.7 \\
\hline 4.0 & 1.2 & 0.6 & 1.2 & 8.9 & 25.2 \\
\hline 6.0 & 1.2 & 0.6 & 1.2 & 7.8 & 25.0 \\
\hline 8.0 & 1.2 & 0.6 & 1.2 & 9.1 & 26.8 \\
\hline 4.0 & 0.3 & 0.6 & 1.2 & 2.9 & 9.0 \\
\hline 4.0 & 0.6 & 0.6 & 1.2 & 4.8 & 15.1 \\
\hline 4.0 & 0.9 & 0.6 & 1.2 & 7.2 & 19.7 \\
\hline 4.0 & 1.2 & 0.6 & 1.2 & 8.9 & 25.2 \\
\hline 4.0 & 1.5 & 0.6 & 1.2 & 10.9 & 31.0 \\
\hline 4.0 & 1.8 & 0.6 & 1.2 & 12.7 & 34.6 \\
\hline 4.0 & 1.2 & 0.2 & 1.2 & 4.1 & 13.1 \\
\hline
\end{tabular}




\begin{tabular}{|c|c|c|c|c|c|}
\hline \multirow{2}{*}{$10^{4}\left[\mathrm{MnO}_{4}^{-}\right]\left(\mathrm{moldm}^{-3}\right)$} & \multirow{2}{*}{$10^{2}[$ ATR $]\left(\mathrm{moldm}^{-3}\right)$} & \multirow{2}{*}[\mathrm{H}^{+}]{$\left(\mathrm{moldm}^{-3}\right)$} & \multirow{2}{*}{$I\left(\mathrm{moldm}^{-3}\right)$} & \multicolumn{2}{|l|}{$10^{3} k_{\text {obs }}\left(s^{-1}\right)$} \\
\hline & & & & Perchloric & Sulfuric \\
\hline 4.0 & 1.2 & 0.6 & 1.2 & 8.9 & 25.2 \\
\hline 4.0 & 1.2 & 0.8 & 1.2 & 11.2 & 32.7 \\
\hline 4.0 & 1.2 & 1.0 & 1.2 & 14.0 & 39.8 \\
\hline 4.0 & 1.2 & 1.2 & 1.2 & 17.3 & 47.0 \\
\hline 4.0 & 1.2 & 0.6 & 1.2 & 8.9 & 25.2 \\
\hline 4.0 & 1.2 & 0.6 & 1.4 & 9.1 & 26.0 \\
\hline 4.0 & 1.2 & 0.6 & 1.6 & 8.9 & 24.2 \\
\hline 4.0 & 1.2 & 0.6 & 1.9 & 9.8 & 27.0 \\
\hline 4.0 & 1.2 & 0.6 & 2.2 & 10.1 & 25.8 \\
\hline 4.0 & 1.2 & 0.6 & 2.5 & 9.3 & 27.9 \\
\hline
\end{tabular}

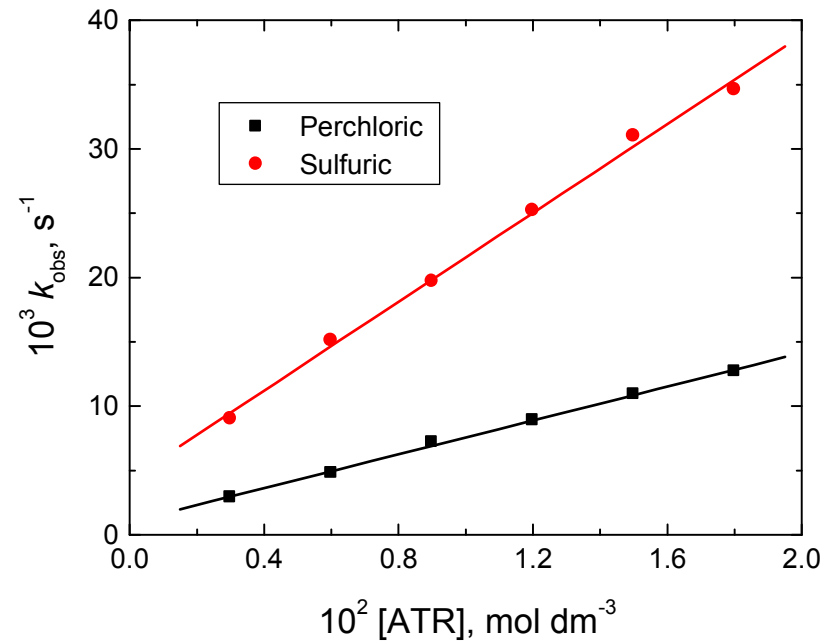

Figure 2. Plots of the observed first order rate constants ( $\left.k_{o b s}\right)$ versus [ATR] in the oxidations of atropine by permanganate ion in perchloric and sulfuric acid solutions. $\left[\mathrm{MnO}_{4}^{-}\right]=4.0 \times 10^{-4},\left[\mathrm{H}^{+}\right]=0.6$ and $\mathrm{I}=1.2 \mathrm{~mol} \mathrm{dm}^{-3}$ at $25^{\circ} \mathrm{C}$.

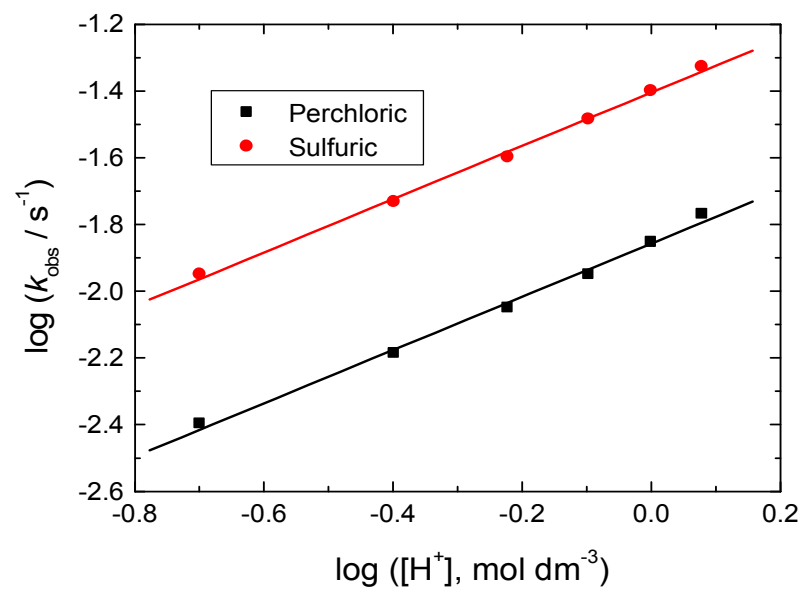

Figure 3. Plots of $\log k_{\text {obs }}$ versus $\log \left[\mathrm{H}^{+}\right]$in the oxidations of atropine by permanganate ion in perchloric and sulfuric acid solutions. $\left[\mathrm{MnO}_{4}^{-}\right]=4.0 x$ $10^{-4},[$ ATR $]=1.2 \times 10^{-2}$ and $\mathrm{I}=1.0 \mathrm{~mol} \mathrm{dm} \mathrm{m}^{-3}$ at $25^{\circ} \mathrm{C}$.

\subsection{Effect of Ionic Strength and Dielectric Constant}

The ionic strength effect has been investigated by varying the concentration of $\mathrm{NaClO}_{4}$ in the reactions media at constant concentrations of permanganate, atropine and acid. It was found that variation in ionic strength did not affect the rates as observed from the data listed in Table 1.
The effect dielectric constant $(D)$ was also studied by varying the acetic acid - water content in the reaction mixture with all other conditions being kept constant. The data clearly revealed that the rate constants did not significantly affected by the decrease in dielectric constant of the solvent mixture; i.e. increase in acetic acid content.

\subsection{Effect of Temperature}

The rates of the reactions were carried out at five different temperatures between 283 and $308 \mathrm{~K}$ at constant concentrations of the reactants and other conditions being constant. The results indicate that the rate constants increased with rise in temperature. The activation parameters of the second order rate constant $\left(k_{2}\right)$ are calculated using Eyring and Arrhenius plots and are listed in Table 2.

Table 2. Activation parameters of the second order rate constant $\left(k_{2}\right)$ in the oxidations of atropine by permanganate ion in perchloric and sulfuric acid solutions. $\left[\mathrm{MnO}_{4}^{-}\right]=4.0 \times 10^{-4},[\mathrm{ATR}]=1.2 \times 10^{-2},\left[\mathrm{H}^{+}\right]=0.6$ and $\mathrm{I}=1.2$ mol $\mathrm{dm}^{-3}$.

\begin{tabular}{lllll}
\hline Acid & $\boldsymbol{\Delta} \boldsymbol{S}^{\ddagger}, \mathbf{J} \mathbf{~ m o l}^{-1} \mathbf{K}^{-1}$ & $\Delta \boldsymbol{H}^{\ddagger}, \mathbf{k J} \mathbf{~ m o l}^{-1}$ & $\Delta \boldsymbol{G}^{\ddagger}{ }_{\mathbf{2 9 8}}, \mathbf{k J ~ m o l}^{-1}$ & $\boldsymbol{E}_{\mathrm{a}}^{\ddagger}, \mathbf{k J ~ m o l}^{-1}$ \\
\hline Perchloric & -112.02 & 52.23 & 85.61 & 51.63 \\
Sulfuric & -104.37 & 48.45 & 79.55 & 47.12 \\
\hline
\end{tabular}

Experimental error $\pm 4 \%$

\subsection{Polymerization Study}

To check the existence of free radicals in the reactions under investigations, the reactions mixtures were mixed with identified quantities of acrylonitrile monomer and kept for 4 hours under nitrogen. On dilution with methanol, white precipitates were formed, indicating the participation of free radicals in the oxidation reactions. The blank experiments which were carried out with either permanganate or atropine with acrylonitrile did not induce polymerization under the same experimental conditions.

\section{Discussion}

The enhancement of the reaction rate with increasing acid concentration and the chemistry of potassium permanganate [31] suggest the formation of a more powerful oxidant, namely permanganic acid, by the equilibrium:

$$
\mathrm{MnO}_{4}{ }^{-}+\mathrm{H}^{+} \stackrel{K_{1}}{\rightleftharpoons} \mathrm{HMnO}_{4}
$$


where $K_{1}$ is the protonation constant of permanganate ion $\left(K_{1}=2.99 \times 10^{-3} \mathrm{dm}^{3} \mathrm{~mol}^{-1}\right.$ at $\left.25^{\circ} \mathrm{C}\right)$ [32]. The protonation of permanganate ion shifts the $\mathrm{Mn}^{\mathrm{VII}} / \mathrm{Mn}^{\mathrm{VI}}$ couple to a more positive value $(+1.3 \mathrm{~V})$, which makes $\mathrm{HMnO}_{4}$ a stronger oxidizing agent than $\mathrm{MnO}_{4}{ }^{-}$[32].

Many investigators [9-17] have suggested that, most of the permanganate oxidation reactions proceed through intermediate complex formation between the oxidant and substrate. In the present work, the kinetic evidences for such complexes were establishedby the linearity of the plots between $1 / k_{\mathrm{obs}}$ and $1 /[\mathrm{ATR}]$, Fig. 4 , in favor of possible formation of a transient complex flanked by oxidant and substrate comparable with the well-known Michaelis-Menten mechanism [33] for enzyme-substrate reactions. The observed insignificant effect of either ionic strength or dielectric constant of the medium on the reactions rates implies association of two neutral molecule [34, 35], i.e. between atropine and acid permanganate.

In view of the above arguments, the following reactions mechanism, illustrated in Scheme 1, can be suggested. The mechanism involves attack of the powerful oxidant, acid permanganate, on the atropine drug leading to the formation of a complex (C) in a prior equilibrium step. The cleavage of such complex leads to the formation of manganite (VI) and a free radical intermediate derived from atropine drug. The latter is attacked by manganite (VI) to yield the corresponding aldehyde as an intermediate product. In a further fast step the intermediate $\mathrm{Mn}(\mathrm{V})$, being very active and unstable in acid medium, reacts with the intermediate product to give the corresponding acid which rapidly hydrolyze [25] to the final oxidation products tropine, phenylmalonic acid and an intermediate Mn (III) species. This step is followed by other fast steps including reactions of atropine with acid permanganate species to form again the final oxidation products and Mn (III) species. The last step is the attack of Mn (III) species on another atropine mole to give the final oxidation products and Mn (II), satisfying the obtained stoichiometry.

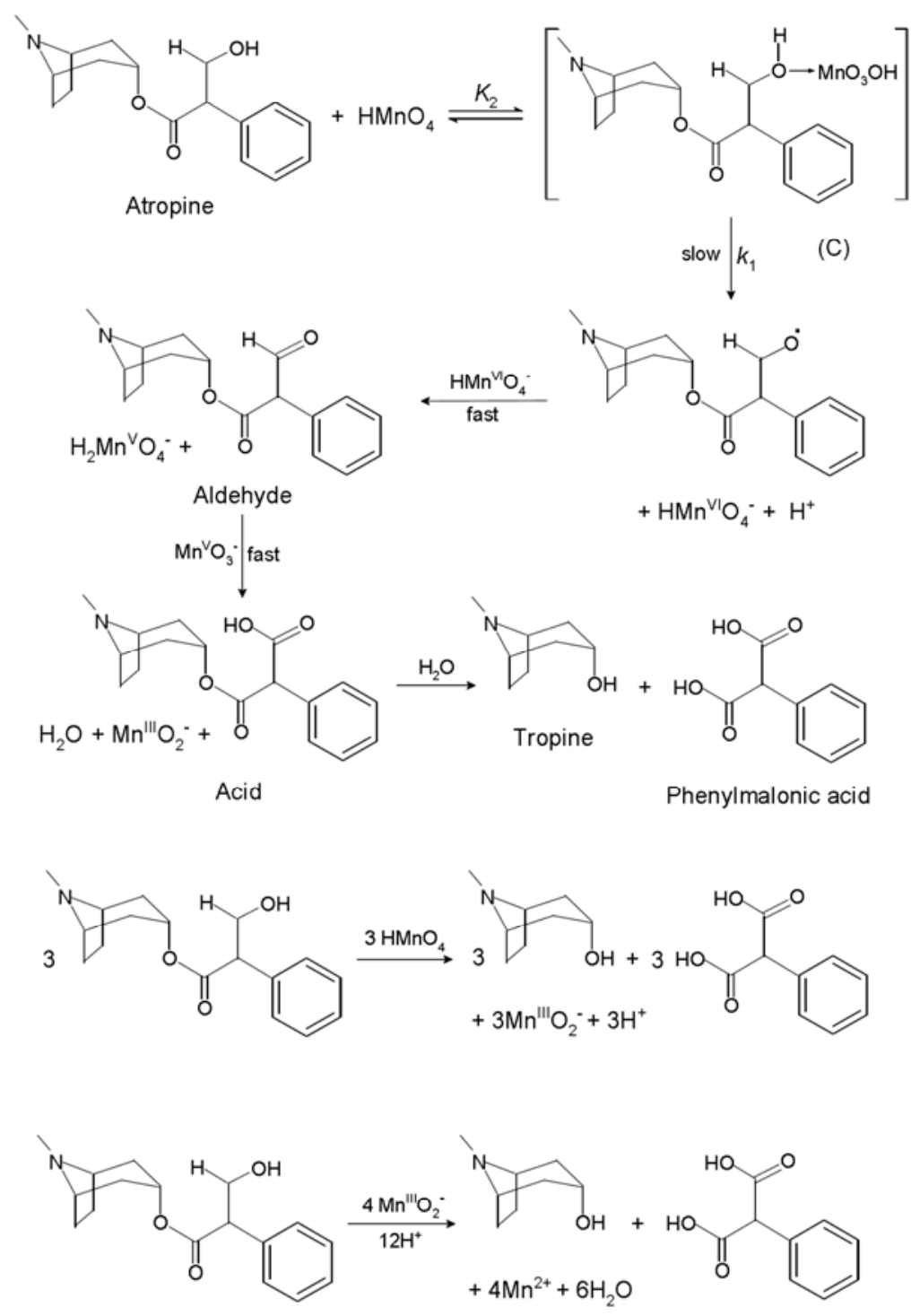

Scheme 1. Mechanism of oxidation of atropine by permanganate ion in acidic media. 
Owing to the proposed mechanistic Scheme 1, the oxidation rate can be expressed by the following rate law:

$$
\text { Rate }=\frac{-d\left[\mathrm{MnO}_{4}^{-}\right]}{d t}=k_{1}[\mathrm{C}]
$$

The relationship between the oxidation rate and the oxidant, substrate and hydrogen ion concentrations is deduced (See Appendix A) to give the following equation:

$$
\text { Rate }=\frac{k_{1} K_{1} K_{2}\left[\mathrm{MnO}_{4}^{-}\right][\mathrm{ATR}]\left[\mathrm{H}^{+}\right]}{1+K_{1}\left[\mathrm{H}^{+}\right]+K_{1} K_{2}[\mathrm{ATR}]\left[\mathrm{H}^{+}\right]}
$$

Under pseudo-first order condition in the presence of a large excess of substrate over that of $\left[\mathrm{MnO}_{4}^{-}\right]$, the rate-law can be expressed by Eq. (3),

$$
\text { Rate }=\frac{-d\left[\mathrm{MnO}_{4}^{-}\right]}{d t}=k_{\mathrm{obs}}\left[\mathrm{MnO}_{4}^{-}\right]
$$

Comparing Eqs. (2) and (3) and rearrangement, the following equations are obtained:

$$
\begin{gathered}
\frac{1}{k_{o b s}}=\left(\frac{1+K_{1}\left[\mathrm{H}^{+}\right]}{k_{1} K_{1} K_{2}\left[\mathrm{H}^{+}\right]}\right) \frac{1}{[\mathrm{ATR}]}+\frac{1}{k_{1}} \\
\frac{1}{k_{o b s}}=\left(\frac{1}{k_{1} K_{1} K_{2}[\mathrm{ATR}]}\right) \frac{1}{\left[\mathrm{H}^{+}\right]}+\left(\frac{1}{k_{1} K_{2}[\mathrm{ATR}]}+\frac{1}{k_{1}}\right)
\end{gathered}
$$

According to Eqs. (4) and (5), other conditions being constant, plots of $1 / k_{\mathrm{obs}}$ versus $1 /[\mathrm{ATR}]$ at constant $\left[\mathrm{H}^{+}\right]$and $1 / k_{\text {obs }}$ versus $1 /\left[\mathrm{H}^{+}\right]$at constant [ATR] should be linear with positive intercepts on the $1 / k_{\text {obs }}$ axes and are indeed found to be so as shown in Figs. 4 and 5, respectively. The slopes and intercepts of such plots lead to calculation of the values of $k_{1}$, $K_{1}$ and $K_{2}$ as listed in Table 3. The obtained values of $K_{1}$ are in a good agreement with those reported in the literature [13, 32].

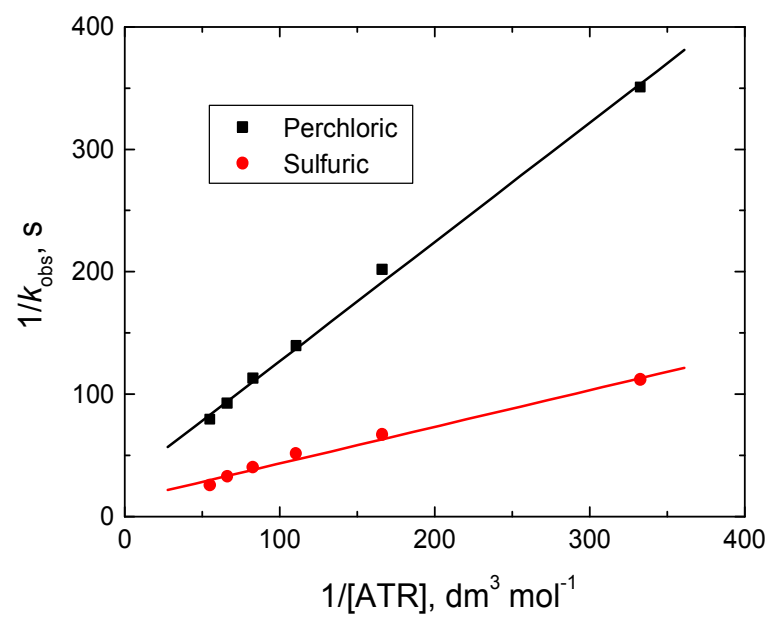

Figure 4. Verification of equation (4) for the oxidations of atropine by permanganate ion in perchloric and sulfuric acid solutions. $\left[\mathrm{MnO}_{4}^{-}\right]=4.0 x$ $10^{-4},\left[H^{+}\right]=0.6$ and $I=1.2 \mathrm{~mol} \mathrm{dm}^{-3}$ at $25^{\circ} \mathrm{C}$.

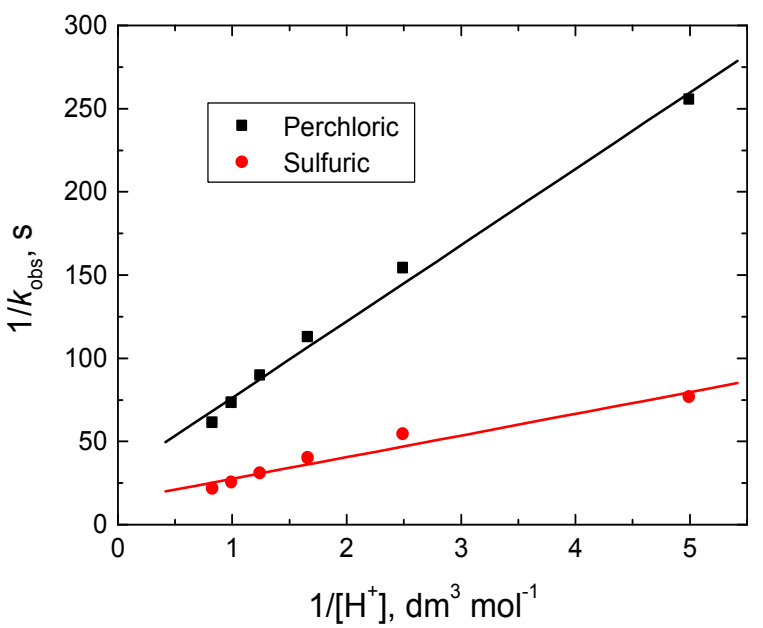

Figure 5. Verification of equation (5) for the oxidations of atropine by permanganate ion in perchloric and sulfuric acid solutions. $\left[\mathrm{MnO}_{4}^{-}\right]=4.0 x$ $10^{-4},[A T R]=1.2 \times 10^{-2}$ and $I=1.2 \mathrm{~mol} \mathrm{dm}^{-3}$ at $25^{\circ} \mathrm{C}$.

Table 3. Values of $k_{1}, K_{1}$ and $K_{2}$ in the oxidations of atropine by permanganate ion in perchloric and sulfuric acid solutions. $\left[\mathrm{MnO}_{4}^{-}\right]=4.0 x$ $10^{-4},[$ ATR $]=1.2 \times 10^{-2},\left[H^{+}\right]=0.6$ and $I=1.2 \mathrm{~mol} \mathrm{dm}^{-3}$ at $25^{\circ} \mathrm{C}$.

\begin{tabular}{llll}
\hline Acid & $\mathbf{1 0}^{\mathbf{3}} \boldsymbol{k}_{\mathbf{1}}, \mathbf{s}^{-\mathbf{1}}$ & $\mathbf{1 0}^{\mathbf{3}} \boldsymbol{K}_{\mathbf{1}}, \mathbf{d m}^{\mathbf{3}} \mathbf{~ m o l}^{-\mathbf{1}}$ & $\mathbf{1 0 ^ { - 3 }} \boldsymbol{K}_{\mathbf{2}}, \mathbf{d m}^{\mathbf{3}} \mathbf{~ m o l}^{-\mathbf{1}}$ \\
\hline Perchloric & 47.59 & 2.78 & 12.91 \\
Sulfuric & 74.10 & 2.93 & 28.13 \\
\hline
\end{tabular}

Experimental error $\pm 4 \%$

The activation parameters listed in Table 2 may be interpreted as follows. The obtained large negative values of $\Delta S^{\ddagger}$ suggest compactness of the formed complexes and such complexes are more ordered than the reactants due to loss of degrees of freedom [36]. Also, the obtained values of $\Delta S^{\ddagger}$ are within the range of radical reactions. The positive values of both $\Delta H^{\ddagger}$ and $\Delta G^{\ddagger}$ confirm endothermic formation of the intermediate complexes and their non-spontaneities, respectively.

\section{Conclusions}

The kinetics of oxidations of atropine by permanganate ion in both perchloric and sulfuric acid solutions has been studied. The main oxidation products of atropine were identified in both cases as the as tropine and phenylmalonic acid. Under comparable experimental conditions, the oxidation rate in sulfuric acid was approximately three times higher than that in perchloric acid. The reactions constants involved in the different steps of the oxidations mechanism along with the activation parameters have been evaluated and discussed.

\section{Acknowledgements}

The Author is highly indebted to the Chemistry Department, Umm Al-Qura University for using of all instrumentation facilities. 


\section{Appendix}

\section{A Derivation of the Rate-Law Expression}

According to the suggested mechanistic Scheme 1:

$$
\begin{gathered}
\text { Rate }=\frac{-d\left[\mathrm{MnO}_{4}^{-}\right]}{d t}=k_{1}[\mathrm{C}] \\
K_{1}=\frac{\left[\mathrm{HMnO}_{4}\right]}{\left[\mathrm{MnO}_{4}^{-}\right]\left[\mathrm{H}^{+}\right]},\left[\mathrm{HMnO}_{4}\right]=K_{1}\left[\mathrm{MnO}_{4}^{-}\right]\left[\mathrm{H}^{+}\right] \\
K_{2}=\frac{[\mathrm{C}]}{[\mathrm{ATR}]\left[\mathrm{HMnO}_{4}\right]}, \\
{[\mathrm{C}]=K_{2}[\mathrm{ATR}]\left[\mathrm{HMnO}_{4}\right]=K_{1} K_{2}\left[\mathrm{ATR}^{-}\right]\left[\mathrm{MnO}_{4}^{-}\right]\left[\mathrm{H}^{+}\right]} \\
\text {Rate }=k_{1} K_{1} K_{2}[\mathrm{ATR}]\left[\mathrm{MnO}_{4}^{-}\right]\left[\mathrm{H}^{+}\right]
\end{gathered}
$$

Substituting Eq. (A.3) into Eq. (A.1) leads to: The total concentration of $\mathrm{MnO}_{4}^{-}$is given by:

$$
\left[\mathrm{MnO}_{4}^{-}\right]_{\mathrm{T}}=\left[\mathrm{MnO}_{4}^{-}\right]_{\mathrm{F}}+\left[\mathrm{HMnO}_{4}\right]+[\mathrm{C}]
$$

where ' $\mathrm{T}$ ' and ' $\mathrm{F}$ ' stand for total and free.

Therefore,

$$
\begin{gathered}
{\left[\mathrm{MnO}_{4}^{-}\right]_{\mathrm{T}}=\left[\mathrm{MnO}_{4}^{-}\right]_{\mathrm{F}}+K_{1}\left[\mathrm{MnO}_{4}^{-}\right]_{\mathrm{F}}\left[\mathrm{H}^{+}\right]} \\
+K_{1} K_{2}\left[\mathrm{MnO}_{4}^{-}\right]_{\mathrm{F}}[\mathrm{ATR}]\left[\mathrm{H}^{+}\right] \\
{[\mathrm{MnO} 4-] \mathrm{F}=\frac{\left[\mathrm{MnO}_{4}^{-}\right]_{\mathrm{T}}}{1+K_{1}\left[\mathrm{H}^{+}\right]+K_{1} K_{2}[\mathrm{ATR}]\left[\mathrm{H}^{+}\right]}}
\end{gathered}
$$

In view of the high concentrations of $\left[\mathrm{H}^{+}\right]$we can write:

$$
\left[\mathrm{H}^{+}\right]_{\mathrm{T}}=\left[\mathrm{H}^{+}\right]_{\mathrm{F}}
$$

Similarly

$$
[\mathrm{ATR}]_{\mathrm{T}}=[\mathrm{ATR}]_{\mathrm{F}}
$$

Substituting Eqs. (A.7), (A.8) and (A.9) into Eq. (A.4) (and omitting ' $\mathrm{T}$ ' and ' $\mathrm{F}$ ' subscripts) leads to:

$$
\text { Rate }=\frac{k_{1} K_{1} K_{2}\left[\mathrm{MnO}_{4}^{-}\right][\mathrm{ATR}]\left[\mathrm{H}^{+}\right]}{1+K_{1}\left[\mathrm{H}^{+}\right]+K_{1} K_{2}[\mathrm{ATR}]\left[\mathrm{H}^{+}\right]}
$$

Under pseudo-first order condition, the rate-law can be expressed by equation (A.11):

$$
\text { Rate }=\frac{-d\left[\mathrm{MnO}_{4}^{-}\right]}{d t}=k_{\mathrm{obs}}\left[\mathrm{MnO}_{4}^{-}\right]
$$

Comparing Eqs. (A.10) and (A.11), we get the following relationship:

$$
k_{\mathrm{obs}}=\frac{k_{1} K_{1} K_{2}[\mathrm{ATR}]\left[\mathrm{H}^{+}\right]}{1+K_{1}\left[\mathrm{H}^{+}\right]+K_{1} K_{2}[\mathrm{ATR}]\left[\mathrm{H}^{+}\right]}
$$

With rearrangement of Eq. (A.12), the following equations are obtained:

$$
\frac{1}{k_{o b s}}=\left(\frac{1+K_{1}\left[\mathrm{H}^{+}\right]}{k_{1} K_{1} K_{2}\left[\mathrm{H}^{+}\right]}\right) \frac{1}{[\mathrm{ATR}]}+\frac{1}{k_{1}}
$$

$$
\frac{1}{k_{o b s}}=\left(\frac{1}{k_{1} K_{1} K_{2}[\mathrm{ATR}]}\right) \frac{1}{\left[\mathrm{H}^{+}\right]}+\left(\frac{1}{k_{1} K_{2}[\mathrm{ATR}]}+\frac{1}{k_{1}}\right)
$$

\section{References}

[1] Kittakoop P, Mahidol C, Ruchirawat S (2014) Alkaloids as important scaffolds in therapeutic drugs for the treatments of cancer, tuberculosis, and smoking cessation. Curr. Top Med. Chem. 14: 239-252.

[2] Cushnie TP, Cushnie B, Lamb AJ (2014) Alkaloids: an overview of their antibacterial, antibiotic-enhancing and antivirulence activities. Int. J. Antimicrob. Agents, 44: 377-386.

[3] Qiu S, Sun H, Zhang AH, Xu HY, Yan GL, Han Y, Wang XJ (2014) Natural alkaloids: basic aspects, biological roles, and future perspectives. Chin. J. Nat. Med. 12: 401-6.

[4] Bartholomew BA, Smith MJ, Trudgill PW, Hopper DJ (1996) Atropine metabolism by pseudomonas sp. Strain AT3: Evidence for nortropine as an intermediate in tropine breakdown and reactions leading to succinate. Appl. Environ. Microbiol. 62: 3245-3250.

[5] Brust J C M (2004) InNeurological aspects of substance aabuse, $2^{\text {nd }}$ (ed.) (Philadelphia: Elsevier) p. 310.

[6] Rörsch A, Berends FA, Bartlema CH, Stevens WF, Winsinck F (1971) The isolation and properties of Pseudomonas strains growing on atropine and producing an atropine esterase, Proc. K. Ned. Akad. Wet. Ser. C 74: 132-147.

[7] Stewart R (1965) Oxidation in Organic Chemistry, Part A (ed.) Wiberg KB, New York, Academic Press.

[8] Jose TP, Nandibewoor ST, Tuwar SM (2005) Mechanism of oxidation of L-histidine by heptavalent manganese in alkaline medium. E-J. Chem. 2: 75 -85.

[9] Fawzy A, Ashour SS, Musleh MA, (2014) Base-catalyzed oxidation of L-asparagine by alkaline permanganate and the effect of alkali-metal ion catalysts: kinetics and mechanistic approach, React. Kinet. Mech. Catal. 111: 443-460.

[10] Fawzy A, Shaaban MR (2014) Kinetic and mechanistic investigations on the oxidation of N'-heteroaryl unsymmetrical formamidines by permanganate in aqueous alkaline medium. Transition Met. Chem. 39: 379-386.

[11] Fawzy A, Zaafarany IA, Alfahemi J, Tirkistani FA (2015) Basecatalyzed oxidation of aminotriazole derivative by permanganate ion in aqueous alkaline medium: a kinetic study. Int. J. Inn. Res. Sci. Eng. Tech. 4: 6802-6814.

[12] AsgharBH, Fawzy A (2014) Kinetic, mechanistic, and spectroscopic studies of permanganate oxidation of azinylformamidines in acidic medium, with autocatalytic behavior of manganese (II). J. Saudi Chem. Soc., in press.

[13] Fawzy A, Ashour SS, Musleh MA (2014) Kinetics and mechanism of oxidation of L-histidine by permanganate ions in sulfuric acid medium. Int. J. Chem. Kinet. 46: 370-381.

[14] Ahmed GA, Fawzy A, Hassan RM (2007) Spectrophotometric evidence for the formation of short-lived hypomanganate $(\mathrm{V})$ and manganite (VI) transient species during the oxidation of $K$ carrageenan by alkaline permanganate. Carbohydr. Res. 342: $1382-1386$. 
[15] Zaafarany IA, Fawzy A, Ahmed GA, Ibrahim SA, Hassan RM, Takagi HD (2010) Further evidence for detection of short-lived transient hypomanganate (V) and manganite (VI) intermediates during oxidation of some sulfated polysaccharides by alkaline permanganate using conventional spectrophotometeric techniques. Carbohydr. Res. 345: 1588-1593.

[16] Hassan RM, Fawzy A, Alarifi A, Ahmed GA, Zaafarany IA, Takagi HD (2011) Base-catalyzed oxidation of some sulfated macromolecules: kinetics and mechanism of formation of intermediate complexes of short-lived manganate (VI) and/or hypomanganate $(\mathrm{V})$ during oxidation of iota- and lambdacarrageenan polysaccharides by alkaline permanganate. J. Mol. Catal. A, 335: 38-45.

[17] Hassan RM, Dahy A, Ibrahim S, Zaafarany IA, Fawzy A (2012) Oxidation of some macromolecules. Kinetics and mechanism of oxidation of methyl cellulose polysaccharide by permanganate ion in acid perchlorate solutions. Ind. Eng. Chem. Res. 51: 5424-5432.

[18] Gardner KA, Kuehnert LL, Mayer JM (1997) Hydrogen atom abstraction by permanganate: oxidations of arylalkanes in organic solvents. Inorg. Chem. 36: 2069-2078.

[19] Perez-Benito JF (2009) Permanganate oxidation of $\alpha$-amino acids: kinetic correlations for the non-autocatalytic and autocatalytic reaction pathways. J. Phys. Chem. 113: 159825989.

[20] Babatunde OAA (2008) study of the kinetics and mechanism of oxidation L-ascorbic acid by permanganate ion in acidic medium. World J. Chem. 3: 27-35.

[21] Day MC, Selbin J (1985) Theoretical Inorganic Chemistry, Reinhold Publishing Corporation, New York, p. 344.

[22] Byadagi KS, Hosahalli RV, Nandibewoor ST, Chimatadar SA (2012) Oxidation of a anticholinergic drug atropine sulfate monohydrate by alkaline copper (III) periodate complex: a kinetic and mechanistic study. Z. Phys. Chem. 226: 233-249.

[23] Byadagi KS, Nandibewoor ST, Chimatadar SA (2013) Catalytic activity of ruthenium (III) on the oxidation of an anticholinergic drug-atropine sulfate monohydrate by copper (III) periodate complex in aqueous alkaline medium decarboxylation and free radical mechanism. ActaChim. Slov., 60: 617-627.
[24] Meti M, Nandibewoor ST, Chimatadar S (2014) Spectroscopic investigation and oxidation of the anticholinergic drug atropine sulfate monohydrate by hexacyanoferrate (III) in aqueous alkaline media: a mechanistic approach, Turk. J. Chem. 38: 477-487.

[25] Abdullah S, Al-Ghreizat S K, Abdel-Halim HM (2015) Kinetics of oxidation of atropine by alkaline $\mathrm{KMnO}_{4}$ in aqueous solutions. Asian J. Chem. 27: 3877-3882.

[26] Do Pham D D, Kelso G F, Yang Y, Hearn M T W (2014) Studies on the oxidative N-demethylation of atropine, the baine and oxycodone using a FeIII-TAML catalyst, Green Chem. 16: 1399-1405.

[27] Vogel IAA (1978) Text Book of Quantitative Inorganic Analysis. $4^{\text {th }}$ Ed. ELBS and Longman, New York, p. 352.

[28] Furniss BS, Hannaford AJ, Smith WG, Tatchell AR (2004) In Vogel's textbook of practical organic chemistry, $5^{\text {th }}$ (ed.) (Pearson Education Ltd).

[29] Vogel AI (1973) In Text book of practical organic chemistry, $3^{\text {rd }}$ (ed.) (London: Longman) p. 332.

[30] Feigl F (1975) Spot tests in organic analysis, p. 195, Elsevier, New York.

[31] Bailey N, Carrington A, Lott T, Symons MCRJ (1960) Structure and reactivity of the oxyanions of transition metals. PartVIII. Acidities and spectra of protonated oxyanions. J. Chem. Soc. 290-297.

[32] Carrington A, Symons MCRJ (1963) Structure and reactivity of the oxyanions of transition metals. Chem. Rev. 63: 443-460.

[33] Michaelis L, Menten ML (1913) The kinetics of invertase action. Biochem. Z., 49: 333-369.

[34] Frost AA, Person RG (1973) Kinetics and mechanism, p. 147, Wiley Eastern, New Delhi.

[35] Amis ES (1966) Solvent effect on reaction rates and mechanism, p. 28, Academic Press, New York.

[36] Weissberger A (1974) In Investigation of rates and mechanism of reactions in techniques of chemistry,(New York: John Wiley \& Sons), p. 421. 